\title{
Note on Translations and Scholarly Conventions
}

I forgo diacritics for the names of people (including authors), places, and Indian-origin terms now part of English. But I retain them for titles of texts and transliterations of phrases, usually from Sanskrit, out of dedication to textual fidelity and accuracy. For potentially unfamiliar terms from Sanskrit and other languages, I generally provide diacritics on first use, and thereafter I omit both diacritics and italics. I make some exceptions and repeat diacritics when I am discussing the linguistic origins or meanings of specific words. Readers can find a glossary of nonEnglish (and newly English) terms at the end of the book. This is an imperfect set of compromises that attempts to reconcile two scholarly commitments - precision and accessibility — that I hold equally dear.

For Sanskrit diacritics, we have an established system that all specialists will recognize. Persian is another story. Here, I use the IJMES transliteration system, with some modifications. I represent al- with approximate pronunciation where appropriate. Citations refer to page numbers unless otherwise marked; I cite some Sanskrit texts using book, chapter, and verse numbers, in accordance with convention (e.g., Mahābhārata I2.200.4O-4I). Sometimes, in pursuit of clarity, I give both page and verse numbers.

In this book I translate a wide variety of Sanskrit texts, inscriptions, and poetry. In so doing, I strive to be faithful to the meaning, sense, and poetry of the original texts. Sanskrit poetry has long suffered from bad translators. In recent decades, many modern Sanskritists have favored overly literal 
translations that transmorph refined Sanskrit verses into clunky, sometimes nearly unintelligible English. I avoid that failed approach here. Instead I strive to create readable, even appealing English renderings that at least nod at the aesthetic beauty of the Sanskrit original. I also prioritize clarity, which sometimes means that I move around clauses and repeat words, especially names. I do not shy away from idiomatic translations when I feel that they capture something important about the original Sanskrit poetry.

I invite readers to be critical of my translations (and of everything else that I write in this book). I also caution that looking up every word in a dictionary and tossing in minimal English grammar, without a thought to aesthetics in the target language, often comes closer to mutilating the original text rather than the art of translation. 